Гильманов Идрис Мухаматюнусович

кандидат юридических наук, доцент кафедры юридических дисциплин Набережночелнинского института Казанского (Приволжского)

федерального университета, судья в отставке

Гильманов Мухамат Мухаматюнусович

кандидат педагогических наук, доцент кафедры педагогики и психологии

Набережночелнинского государственного

педагогического университета

\section{СУДЫ ПЕРВОЙ ИНСТАНЦИИ \\ ПО УГОЛОВНЫМ ДЕЛАМ РЕСПУБЛИКИ КАЗАХСТАН: ВОПРОСЫ ПОДСУДНОСТИ И ДЕЛ ЧАСТНОГО ОБВИНЕНИЯ}

\section{Аннотация:}

Общеизвестно, что международные документы содержат требования о соблюдении правил подсудности, действующих и в Казахстане. В cm. 10 Уголовного кодекса Республики законодатель предусмотрел понятие "уголовный проступок», а за его совершение - максимальное наказание в виде ареста. Конечно, возможен и другой вариант в виде применения отдельной статьи «Уголовные проступки». Однако в УПк нужно прописать упрощенное (суммарное) производство, несмотря на наличие ускоренного досудебного расследования согласно cm. 190 УПК РК. Большинство государств убедилось в практичности и экономической эффективности для бюджета использования упрощенной процедуры на стадиях производства дознания, предварительного и судебного следствия. Упрощенный и ускоренный варианты позволяют сэкономить время, необходимое для рассмотрения более сложных дел, серьезно снизить как судебные расходы, так и затраты при сборе доказательств на досудебном этапе раскрытия. В рамках исследования авторы сравнивают казахстанское законодательство с положениями УПК РФ. Изучены вопросы подсудности судов по уголовным делам на территории России, исходя из содержания статьи 31 УПК РФ. В работе дается перечень составов преступлений Уголовного кодекса РФ. Таким образом, ни один состав преступления не может остаться не охваченным и не распределенным. Последствием обнаружения нарушений правил подсудности является автоматическая отмена приговора.

\section{Ключевые слова:}

судебная система, подсудность судов, суды первой инстанции, следственный судья, проступок, категории преступлений, преступления небольшой тяжести, дела частного обвинения.

\section{Gilmanov Idris Mukhamatyunusovich}

PhD in Law, Associate Professor, Department of Legal Disciplines, Naberezhnye Chelny Institute, branch of Kazan

Federal University, Retired Judge

Gilmanov Mukhamat Mukhamatyunusovich

$\mathrm{PhD}$ in Education Science, Associate Professor, Department of Education Science and Psychology, Naberezhnye Chelny State Pedagogical University

\section{CRIMINAL COURTS OF FIRST INSTANCE IN THE REPUBLIC OF KAZAKHSTAN: JURISDICTION AND PRIVATE PROSECUTION}

Summary:

It is a well-known fact that international instruments include the requirements of compliance with the rules of jurisdiction which are carried out by the legislator of Kazakhstan. In Article 10 of the Criminal Code of Kazakhstan, the legislator has provided for the concept of misdemeanor and arrest as the maximum punishment for committing it. Another option implies the application of misdemeanor as a separate article. However, it is necessary to provide for summary procedure despite the availability of accelerated pre-trial investigation stipulated in Article 190 of the Criminal Procedure Court of the Republic of Kazakhstan. Most states have become convinced of the practicality and cost-effectiveness of summary procedure at inquiry, pre-trial, and trial stages. Simplified and expedited options save time needed to deal with more complex cases and reduce both court and pre-trial costs. The authors compare Kazakh laws with Russian legislation. They examine the jurisdiction of criminal courts in Russia based on Article 31 of the Criminal Procedure Code of the Russian Federation. The study presents a list of corpora delicti of the Criminal Code of the Russian Federation. Thus, no corpus delicti can remain unreached and undistributed. If one reveals that the rules of jurisdiction have been violated, the verdict will be automatically canceled.

Keywords: judiciary, jurisdiction of courts, courts of first instance, investigating magistrate, misdemeanor, categories of crimes, minor offenses, private prosecution.

Согласно ст. 7 Конституции Республики Казахстан государственным языком является казахский, также наравне с ним употребляется русский. Вопросам суда и правосудия в Конституции посвящен раздел 7, в который входят статьи 75-83. Так, в ст. 75 указывается, что суды используют уголовные, гражданские и иные формы судопроизводства [1]. 
Уголовный кодекс Республики Казахстан № 226-V был принят 3 июля 2014 г. и вступил в законную силу с 1 января 2015 г. В ст. 467 УК РК признается утратившим силу предыдущий Уголовный кодекс от 16 июля 1997 г. В отличие от ст. 14 УПК Российской Федерации ст. 10 УК Республики Казахстан содержит определения понятий «преступление» и «уголовный проступок» [2]. В качестве последнего признается совершенное виновно деяние (действие или бездействие), не представляющее большой общественной опасности, причинившее незначительный вред либо создавшее угрозу причинения вреда личности, обществу или государству, за совершение которого предусмотрено наказание в виде штрафра, привлечения к общественным работам, исправительных работ или ареста. Например, УК Туркменистана не включает категорию «уголовный проступок» [3], тогда как в России ведется обсуждение нормативного закрепления этого термина [4].

В перечне наказаний за совершение уголовного проступка в УК РК лишение свободы не значится. Объяснением, на наш взгляд, служит отсутствие в судебной системе Казахстана мировых судей. В связи с наличием в России мировой юстиции в ст. 14 действующего Уголовного кодекса РФ целесообразно ввести понятие «уголовный проступок», соответственно изменить заголовок статьи, а также дать определение, подобное казахстанскому, с внесением в перечень видов наказаний лишения свободы на срок до 1 года. Такая дополнительная диффференциация объективно необходима, так как все уголовные проступки будут отнесены к подсудности мировых судей.

Кроме того, мы предлагаем возврат в ч. 1 ст. 31 УПК РФ максимального наказания, которое может назначить мировой судья, - до 2 лет лишения свободы (а не 3 года). Именно этот срок (до 2 лет) был оговорен в ч. 1 ст. 467 УПК РСФСР в первое время функционирования мировой юстиции, когда сложно было предвидеть все возрастающую нагрузку последней [5, с. 205].

Категории преступлений утверждены в ст. 11 УК РК. К преступлениям небольшой тяжести относятся умышленные деяния, за совершение которых предусмотрено максимальное наказание до 2 лет лишения свободы (в ст. 15 УК РФ - до 3 лет), а также неосторожные деяния - до 5 лет лишения свободы. Преступлениями средней тяжести признаются умышленные деяния, за совершение которых следует максимальное наказание не свыше 5 лет лишения свободы, а также неосторожные деяния - свыше 5 лет лишения свободы (в России - более 3 лет). К тяжким преступлениям относятся умышленные деяния, за совершение которых предусмотрено максимальное наказание не свыше 12 лет лишения свободы (в РФ - до 10 лет), за совершение особо тяжких преступлений - свыше 12 лет.

В России, на наш взгляд, назрела объективная необходимость пересмотра категориального аппарата. Так, в ч. 2 ст. 15 УК мы предлагаем максимальный предел преступлений небольшой тяжести с 3 лет лишения свободы снизить до 2 лет, предусмотренных ранее - до 2011 г. [6, с. 7; 7].

Действующий Уголовно-процессуальный кодекс Республики Казахстан от 4 июля 2014 г. № 231-V ЗРК вступил в законную силу с 1 января 2015 г. [8], т. е. одновременно с Уголовным кодексом РК. Новый УПК отменил ранее действовавший УПК от 13 декабря 1997 г.

Судам посвящена глава 7 нового УПК, которая состоит из ст. 51-57. В ч. 2 ст. 51 среди правил первым пунктом рассмотрения уголовных дел значатся определение их подсудности, а также формирование состава суда. В ч. 3 перечислены все суды, осуществляющие правосудие по уголовным делам: 1) Верховный суд Республики Казахстан; 2) областные и приравненные к ним суды, Военный суд; 3) районные и приравненные к ним суды; специализированные межрайонные суды по уголовным делам, специализированные межрайонные военные суды по уголовным делам, специализированные межрайонные суды по делам несовершеннолетних, военные суды гарнизонов. Мировых судей в судебной системе страны нет. В России мировые судьи функционируют с 2000 г. [9, с. 28-29, 212-214]. В 2006 г. Х.М. Гафуров предлагал ввести мировых судей в Республике Таджикистан. В свое время в Италии мировые судьи (джудичи) заменили преторов [10]. На наш взгляд, объективных условий для введения мировых судей в Казахстане нет, однако в будущем они могут появиться.

Вопросы о составе суда определяются в ст. 52 УПК 2014 г. Уголовные дела в судах первой инстанции рассматриваются единолично судьей, уголовные дела по апелляционной жалобе судом в составе трех судей.

Проблемам подсудности уголовных дел посвящалась глава 38 (Раздел 7. Производство в суде первой инстанции), которая состояла из ст. 290-298 УПК. В частности, в ст. 290 указывается, что районные и приравненные к ним суды разбирают все уголовные дела, кроме отнесенных к юрисдикции областного и приравненного к нему суда. В ст. 291 приведен перечень 17 статей УК РК, в санкциях которых есть смертная казнь, а также фигурируют дела о применении принудительных мер медицинского характера.

В действующем Уголовно-процессуальном кодексе Казахстана вопросам подсудности посвящена глава 40, входящая в раздел 7 «Подсудность уголовных дел в суде первой инстанции». Подсудность районному и приравненному к нему суду регламентирует ст. 306 УПК РК. К специализированным судам относится специализированный межрайонный суд по делам несовершеннолетних. 
В штатной структуре судов Казахстана предусмотрены следственные судьи, которых в РФ нет (в царской России были). В предыдущем УПК РК такая должность также отсутствовала. Полномочия следственного судьи перечислены в ст. 55 УПК РК. Эти функции законодатель не стал передавать мировым судьям, а включил их в обязанности судей районных (городских) судов. В качестве одной из причин называлась наибольшая опытность судей второй инстанции. На наш взгляд, такое решение принято совершенно правильно, однако основной причиной послужила постоянно возрастающая нагрузка мировых судей. Именно поэтому нет необходимости как пересматривать данный вопрос, так и вводить отдельный штат следственных судей, что не вызовет новых финансовых затрат из бюджета.

В гл. 3 раскрываются вопросы уголовного преследования. Так, в ст. 32 УПК Казахстана определены дела частного обвинения, а именно - дается перечень 20 составов преступлений, отнесенных к подобным делам: ст. 108 «Умышленное причинение легкого вреда здоровью» с наказанием в виде исправительных работ и штрафа; ст. 109 «Побои» с аналогичным наказанием; ч. 1 ст. 110 «Истязание» - до 2 лет лишения свободы; ч. 1, 2 ст. 114 «Неосторожное причинение вреда здоровью» с наказанием в виде штрафа и исправительных работ; ст. 123 «Принуждение к половому сношению...» - до 1 года лишения свободы; ч. 1-3 ст. 130 «Клевета» - до 3 лет лишения свободы; ч. 1, 2 ст. 131 «Оскорбление» - исправительные работы; ч. 1, 2 ст. 147 «Нарушение неприкосновенности частной жизни...» - до 3 лет лишения свободы; ч. 1 ст. 149 «Нарушение неприкосновенности жилища»; ч. 1 ст. 150 «Воспрепятствование осуществлению избирательных прав...», ч. 1, 2 ст. 152 «Нарушение трудового законодательства», ч. 1 ст. 198 «Нарушение авторских и (или) смежных прав», ч. 1 ст. 199 «Нарушение прав на изобретения, полезные модели...» с наказанием в виде штрафа; ч. 1 ст. 321 «Разглашение врачебной тайны».

Согласно ст. 33 предыдущего УПК от 13 декабря 1997 г., к делам частного обвинения относился 21 состав преступлений: ч. 1-3 ст. 105 «Доведение до самоубийства» с наказанием до 3 лет лишения свободы; ст. 111 «Причинение вреда здоровью в состоянии аффекта» с наказанием в виде исправительных работ; ст. 123, 129 «Клонирование человека»; ст. 130 «Клевета»; ч. 1, 2 ст. 136 «Подмена ребенка»; ч. 1, 2 ст. 140 «Неисполнение обязанностей по воспитанию несовершеннолетнего» с наказанием в виде исправительных работ; ст. 142 «Злоупотребление правами опекуна или попечителя»; ч. 1, 2 ст. 144 «Вовлечение несовершеннолетних в изготовление продукции эротического содержания»; ч. 1 ст. 145 «Нарушение равноправия человека и гражданина»; ч. 1 ст. 188 «Кража» - до 3 лет лишения свободы; ч. 1 ст. 300 «Незаконное культивирование запрещенных... растений...» УК РК с наказанием до 2 лет лишения свободы.

При сопоставлении двух перечней видно, что совпадают лишь два состава преступлений: ст. 123 и 130 УК. Однако по непонятной причине национальный законодатель исключил кражу. В России обсуждают вопрос о включении ч. 1 ст. 158 «Кража» в перечень дел частного обвинения. На наш взгляд, части 1, 2 ст. 140 «Неисполнение обязанностей по воспитанию несовершеннолетнего» также нельзя было удалять из списка.

Для сравнения, в ч. 2 ст. 20 УПК РФ предусмотрены лишь три состава преступлений, отнесенные к делам частного обвинения: 1) ч. 1 ст. 115 «Умышленное причинение легкого вреда здоровью» с максимальным наказанием до 1 года исправительных работ; 2) ч. 1 ст. 116 «Нанесение побоев лицом, подвергнутым административному наказанию» - до 6 месяцев исправительных работ; 3) ч. 1 ст. 128 «Клевета» УК РФ.

Следует согласиться с Ф. Багаутдиновым, указывающим, что определить в УПК РФ перечень составов преступлений «будет непросто» [11]. В 2002 г., когда этот исследователь предлагал расширение частных начал в разумных пределах, в УПК к делам частного обвинения относилось 5 составов преступлений из 520. Такое количество автор назвал мизерным, что реально отражало картину. Если в предыдущем УПК Казахстана был 21 состав преступлений, а в ныне действующем стало 20, то нам можно на это ориентироваться.

Отдельные российские ученые-процессуалисты выдвигают предложение из ч. 3 ст. 20 УПК РФ исключить категорию уголовных дел частно-публичного обвинения, переведя эти 9 составов в категорию дел частного обвинения. Таким образом, в сумме получилось бы 12 составов преступлений. Однако полностью с этим предложением согласиться нельзя, поскольку необходимо учитывать отдельные немаловажные нюансы. Например, два состава преступлений (ст. 131 и 132 УК с санкцией от 3 до 6 лет лишения свободы) из гл. 18 УК относятся к подсудности районных (городских) судов, поэтому их включать нельзя. При этом еще один состав преступления из ч. 1 ст. 147 «Нарушение изобретательских и патентных прав» с максимальным наказанием до 2 лет лишения свободы тоже относится к подсудности районных (городских) судов, его также переводить в перечень дел частного обвинения нельзя. Это несмотря на то, что часть 1 ст. 116 УК была отнесена к подсудности районных (городских) судов, чтобы исключить случаи применения правил административной преюдиции. 
Прежде чем начать фрормировать перечень составов преступлений, отнесенных к делам частного обвинения, необходимо определиться с максимальным наказанием. Первый вариант до 1 года лишения свободы - чаще встречается в Европе, например в УПК Польши [12]; второй до 2 лет лишения свободы - был принят во Франции [13]. На основании Закона о модернизации в этой стране с июля 2017 г. мировые судьи (juge de proximite) перестали рассматривать уголовные дела [14]. На наш взгляд, учитывая своеобразие России, увеличившей максимальное наказание с 2 до 3 лет лишения свободы, которое может назначить мировой судья, необходимо избрать французский вариант - до 2 лет лишения свободы. Данное предложение будет объективно соответствовать российской действительности.

С учетом максимального наказания можно предложить следующий проект перечня из 9 составов преступлений для дел частного обвинения (хотя в реальности население не готово защищать свои нарушенные права самостоятельно): 1) ч. 1 ст. 115, 2) ч. 2 ст. 115, 3) ст. 116, 4) ч. 1 ст. 119, 5) ч. 1 ст. 128.1, 6) ч. 2 ст. 128.1, 7) ч. 1 ст. 146, 8) ч. 2 ст. 146, 9) ч. 1 ст. 147 УК РФ. В зависимости от успешности применения гражданами на практике указанных 9 составов можно перейти ко второму этапу расширения данного списка до 20 составов. Среди них следует выделить: 1) ч. 1 ст. 137,2 ч) ч. 1 ст. 138,3$)$ ч. 1 ст. 139, 4) ч. 2 ст. 139, 5) ст. 140, 6) ч. 1 ст. 144, 7) ст. 145, 8) ст. 155, 9) ч. 1 ст. 165, 10) ч. 1 ст. 167, 11) ч. 1 ст. 168 УК РФ. Тогда количество составов преступлений, отнесенных УПК РФ к делам частного обвинения, совпадет с таковым в Казахстане. Однако сейчас определить период, требуемый для достижения сознанием населения соответствующего уровня, который позволял бы гражданам самостоятельно защищать нарушенные права, не представляется возможным.

Рассмотрим Конституционный закон Республики Казахстан от 25 декабря 2000 г. № 132-11 «О судебной системе и статусе судей Республики Казахстан» [14]. Статья 3 указанного документа посвящена судебной системе, которая состоит из Верховного суда РК, местных и других судов. В ч. 2 обозначенной статьи дается перечень местных судов: 1) областные и приравненные к ним суды; 2) районные и приравненные к ним суды (городской суд, межрайонный суд). В ч. 3 приведены специализированные суды: военные, финансовые, экономические, административные, по делам несовершеннолетних и др.

Глава 1 раздела 2 именуется «Районные и приравненные к ним суды» и состоит из ст. 6-9. Согласно ст. 6 районные и приравненные к ним суды формируются президентом страны. Аналогичная схема действует и для определения общего числа судей судов первой инстанции.

В ст. 8 предусмотрены полномочия районных судов, которые выполняют функции суда первой инстанции, т. е. основного звена, и рассматривают дела и материалы, отнесенные к его подсудности, а также осуществляют другие полномочия, оговоренные в Уголовно-процессуальном кодексе.

Статья 12 КЗ регламентирует, что областные и приравненные к ним суды, т. е. суды среднего звена, рассматривают дела и материалы, отнесенные к его подсудности, изучают судебную практику, осуществляет другие полномочия, предусмотренные законом.

В ст. 32 УПК Казахстана приводится перечень 20 составов преступлений, отнесенных к делам частного обвинения. На наш взгляд, российский список дел частного обвинения, состоящий из 7 составов (ч. 2 ст. 20 УПК РФ), должен быть расширен до 19, т. е. их число предлагается увеличить почти в 3 раза. Несмотря на это, количество составов не возрастет, они просто перейдут в категорию дел частного обвинения. Тем более что по таким делам доля случаев примирительного исхода более высока. Трехкратное увеличение, без сомнения, приведет к существенному снижению служебной нагрузки мировых судей России. За счет экономии фринансовых затрат из бюджета данная мера имеет особое значение, поскольку позволяет добавлять новые судебные участки по всей стране. В результате становится возможным претворить в жизнь важный принцип доступа населения к правосудию.

Выдвигаемые нами предложения могут оказать реальную помощь по существенному снижению служебной нагрузки мировых судей России. Подобные меры, направленные на преодоление нагрузки от возрастающего количества уголовных дел, внедрены в американской уголовной судебной системе в виде сделки о признании вины. В настоящее время исследователи приходят к выводу, что если бы законодатель своевременно не принял такого решения, то функционировавшая в то время система могла разрушиться. Следовательно, практичность законодателя позволила спасти уголовную судебную систему целой страны.

\section{Ссылки:}

1. Конституция Республики Казахстан [Электронный ресурс] // Официальный сайт президента Республики Казахстан. URL: http://www.akorda.kz/ru/official_documents/constitution (дата обращения: 01.08.2019). 
2. Penal Code of the Republic of Kazakhstan [Электронный ресурс] : 3 July 2014 no. 226-V of the Law of the Republic of Kazakhstan // Legal information system of Regulatory Legal Acts of the Republic of Kazakhstan. URL: http://adilet.zan.kz/eng/docs/K1400000226 (дата обращения: 01.08.2019).

3. Об утверждении и введении в действие Уголовного кодекса Туркменистана [Электронный ресурс] : от 12 июня 1997 г. № 222-1 // Legislationline.org. URL: https://www.legislationline.org/ru/documents/action/popup/id/14380/preview (дата обращения: 01.08.2019).

4. Нагорная М. О введении института уголовного проступка [Электронный ресурс] // Адвокатская газета : орган Федеральной палаты адвокатов РФ. 2019. 13 февр. URL: https://www.advgazeta.ru/diskussii/o-vvedenii-instituta-ugolovnogoprostupka (дата обращения: 01.08.2019).

5. Уголовно-процессуальный кодекс РСФСР от 27 октября 1960 г. с внесенными в него изменениями и дополнениями. M., 2000. 240 C.

6. Уголовный кодекс Российской Федерации. М., 2007. 192 с.

7. Уголовный кодекс РФ [Электронный ресурс] : с изм. от 29 июля 2018 г. // Консорциум Кодекс : электронный фронд правовой и нормативно-технической документации. URL: http://docs.cntd.ru/document/9017477 (дата обращения: 01.08.2019).

8. Уголовно-процессуальный кодекс Республики Казахстан [Электронный ресурс] : от 4 июля 2014 г. № 231-V 3РК // Информационно-правовая система нормативных правовых актов Республики Казахстан. URL: http://adilet.zan.kz/eng/docs/K1400000231 (дата обращения: 01.08.2019).

9. Уголовно-процессуальный кодекс РФ по состоянию на 15 февр. 2018 г. М., 2018. 352 с.

10. Гафуров Х.М. Судебная система Республики Таджикистан (сравнительно-правовой анализ) : дис. ... канд. юрид. наук. М., 2006. 198 с. ; Riedel E., Egger F. Handbuch der internationalen Zwangsvollstreckung. Kissing, 1998. Bd 2, t. 3. Italien Kap. II. S. 3.

11. Багаутдинов Ф. Расширение частных начал в уголовном процессе // Российская юстиция. 2002. № 2. С. 32-34.

12. Poland Code of Criminal Procedure [Электронный ресурc] : Act of 6 June 1997. Pt I // Global-regulation.com. URL: https://www.global-regulation.com/translation/poland/7050083/the-act-of-6-june-1997.-the-code-of-criminal-procedure.html (дата обращения: 01.08.2019).

13. France Code de procédure pénale [Электронный ресурc] : Version consolidée au 27 juillet 2019 // Legifrance.gouv.fr. URL: https://www.legifrance.gouv.fr/affichCode.do?cidTexte=LEGITEXT000006071154 (дата обращения: 01.08.2019).

14. The Modernization of Justice in the 21st Century: a Synthesis of Key Measures on 20 November 2016, the Law [Электронный ресурс] // Pennec \& Michau. URL: http://www.pennec-michau.com/nl/2017/09/07/loi-de-modernisation-dela-justice-du-xxie-siecle-n-2016-1547-du-18112016-synthese-des-principales-mesures (дата обращения: 01.08.2019).

\section{References:}

Bagautdinov, F 2002, 'Expansion of Private Principles in the Criminal Process', Rossiyskaya yustitsiya, no. 2, pp. 32-34, (in Russian). 'Criminal Procedure Code of the Republic of Kazakhstan dated July 4, 2014 No. 231-V of the Law of the Republic of Kazakhstan' 2019, Legal Information System of Regulatory Legal Acts of the Republic of Kazakhstan, viewed 01 August 2019, <http://adilet.zan.kz/rus/docs/K1400000231>, (in Russian).

France Code de procédure pénale: Version consolidée au 27 juillet 2019 2019, Legifrance, viewed 01 August 2019, <https://www.legifrance.gouv.fr/affichCode.do?cidTexte=LEGITEXT000006071154>

Gafurov, KhM 2006, Judiciary of the Republic of Tajikistan (A Comparative Legal Analysis), PhD thesis, Moscow, 198 p., (in Russian). Nagornaya, M 2019, 'On Introduction of the Institution of Misdemeanor' 2019, Advokatskaya gazeta: organ Federal'noy palaty advokatov RF, February 13, viewed 01 August 2019, <https://www.advgazeta.ru/diskussii/o-vvedenii-instituta-ugolovnogoprostupka>, (in Russian)

On Approval and Enforcement of the Criminal Code of Turkmenistan as of June 12, 1997 No. 222-1 2019, Legislationline, viewed 01 August 2019, <https://www.legislationline.org/ru/documents/action/popup/id/14380/preview>, (in Russian).

Poland Code of Criminal Procedure: Act of 6 June 1997. Pt I 2019, Global-regulation, viewed 01 August 2019, <https://www.global-regulation.com/translation/poland/7050083/the-act-of-6-june-1997.-the-code-of-criminal-procedure.html>.

'Penal Code of the Republic of Kazakhstan: 3 July 2014 no. 226-V of the Law of the Republic of Kazakhstan' 2019, Legal Information System of Regulatory Legal Acts of the Republic of Kazakhstan, viewed 01 August 2019, <http://adilet.zan.kz/eng/docs/K1400000226>.

Riedel, E \& Egger, F 1998, Handbuch der internationalen Zwangsvollstreckung, Kissing, Bd 2, t. 3. Italien Kap. II, S. 3.

'The Constitution of the Republic of Kazakhstan' 2019, Official Website of the President of the Republic of Kazakhstan, viewed 01 August 2019, <http://www.akorda.kz/ru/official_documents/constitution>, (in Russian).

The Criminal Code of the Russian Federation 2007, Moscow, 192 p., (in Russian).

'The Criminal Code of the Russian Federation as amended on July 29, 2018' 2019, Konsortsium Kodeks: elektronnyy fond pravovoy i normativno-tekhnicheskoy dokumentatsii, viewed 01 August 2019, <http://docs.cntd.ru/document/9017477>, (in Russian). The Criminal Procedure Code of the Russian Federation as of February 15, 2018 2018, Moscow, 352 p., (in Russian).

The Modernization of Justice in the 21st Century: a Synthesis of Key Measures on 20 November 2016, the Law 2019, Pennec \& Michau, viewed 01 August 2019, <http://www.pennec-michau.com/nl/2017/09/07/loi-de-modernisation-de-la-justice-du-xxiesiecle-n-2016-1547-du-18112016-synthese-des-principales-mesures>.

The RSFSR Criminal Procedure Code as of October 27, 1960 with Further Amendments and Supplements 2000, Moscow, 240 p., (in Russian). 